\title{
AVA Nexus e a Produção Discente em Rede na Graduação da ECA-USP: Da Informação ao Conhecimento
}

\author{
Brasilina Passarelli ${ }^{1}$ e Fabiana Grieco Cabral de Mello Vetritti² \\ 'Departamento de Informação e Cultura da Escola de Comunicações e Artes da Universidade de São Paulo \\ ²Programa de Pós-Graduação em Ciências da Comunicação da Escola de Comunicações e Artes da Universidade de São Paulo \\ * Autora para correspondência: fabianagrieco@usp.br
}

\section{RESUMO}

A concepção e a implantação do AVA Nexus - da Informação ao Conhecimento (http://nexus.futuro.usp.br) no âmbito das disciplinas Recursos Informacionais I e II, para os alunos de quarto e quinto períodos do curso de Graduação em Biblioteconomia e Documentação da Escola de Comunicações e Artes da Universidade de São Paulo (ECA-USP), nos anos 2000, constituíram um projeto de vanguarda, estimulando o hibridismo de cursos presenciais ancorados em um AVA - Ambiente Virtual de Aprendizagem, e funcionando como plataforma de publicação de atividades individuais e coletivas dos alunos e também como LOR (learning objects repository), repositório de objetos de aprendizagem. Este artigo visa a caracterizar o AVA, bem como a apresentar indicadores da produção discente individual e coletiva ao longo de mais de treze anos (2002-2015). Com o presente trabalho espera-se contribuir para o debate acerca da importância dos repositórios de objetos de aprendizagem e dos AVAs na construção de um novo conjunto de MIL - Literacias de Mídia e Informação entre os estudantes de graduação da ECA-USP e, por extensão, das instituições de ensino superior (IES) que se utilizam da metodologia de blended learning em cursos presenciais.

Palavras-chave: Nexus; Repositório de Objetos de Aprendizagem; Ambientes Virtuais de Aprendizagem; Produção Discente em Rede; MIL - Literacias de Mídia e Informação.

\begin{abstract}
The conception and implementation of VLE NEXUS - from Information to Knowledge (http://nexus.futuro. usp.br) is based on the disciplines Information Resources I and II, devoted to the 4th and 5th semester students of the Librarianship and Documentation Undergraduate course at the School of Communications and Arts of the Universidade de São Paulo (ECA-USP). It was implemented in the 2000s, and at that time it was an avant-garde project, stimulating the hybrids face-to-face courses anchored in a VLE - Virtual Learning Environment and functioning as platform for publishing individual and collective activities of students and also as learning objects repository (LOR). This article aims to characterize the VLE, as well as to present indicators of individual and collective student production over thirteen years (2002-2015). With this work we hope to contribute to the debate about the importance of learning objects repository and of VLE in the construction of a new set of MIL - Media and Information Literacy among the undergraduate students of ECA-USP and, by extension, higher education institutions (HEIs) that use blended learning methodology in face-to-face courses.
\end{abstract}

Keywords: Nexus; Learning Objects Repository; Virtual Learning Environment; Networked Student Knowledge Production; MIL - Media and Information Literacy.

\section{No Caldo do Contemporâneo Hiperconectado}

A reconfiguração das relações sociais, das estruturas de poder, da economia e, sobretudo, da educação originada pela conectividade da internet se faz necessária e urgente desde os primórdios do ano 2000, quando a internet comercial passou a ser utilizada no Brasil. Diariamente ocorrem fenômenos associados aos avanços das Tecnologias da Informação e Comunicação (TIC) nos processos de mediação da informação e da comunicação. 
Assim, desenham-se novas lógicas e novas semânticas que buscam acompanhar as reconfigurações das relações sociais dos atores em rede (LATOUR, 2005).

Esses atores em rede participam do processo de ressignificação da vida cotidiana, de modo que as TIC se tornaram forças ambientais que criam e transformam nossas realidades. Nesse contexto, Floridi (2013) cunha o conceito de "onlife" para ressignificar essas práticas diárias imbuídas de hiperconectividade. No documento "The Onlife Manifesto", que culminou na publicação do livro The Onlife Manifesto: Being Human in a Hyperconnected Era, são apresentadas quatro transformações sociais transversais: a não diferenciação de realidade on-linel off-line; a não diferenciação entre humanos, máquinas e natureza; a abundância de informação em lugar da escassez de informação anterior; a transição de artefatos estanques, propriedade e relações binárias para a primazia de interações, processos e redes.

Nesses processos de transmutações do contemporâneo hiperconectado, cada vez mais "onlife", emergem novos conjuntos de habilidades e/ou competências, provenientes do uso de diferentes tecnologias digitais. Diante dessa emergência, observa-se a dedicação de estudiosos, do mundo todo, para levarem a cabo investigações acerca do comportamento da população em rede no contemporâneo hiperconectado. No Brasil, esse tema é objeto de investigação dos pesquisadores do Núcleo das Novas Tecnologias de Comunicação Aplicadas à Educação - Nace Escola do Futuro USP. Em 2007, a Professora Titular da Escola de Comunicações e Artes da Universidade de São Paulo (ECA-USP), e coautora deste artigo, Brasilina Passarelli assumiu a coordenação científica do Núcleo e inaugurou o Observatório da Cultura Digital, locus que se dedica a desenvolver pesquisas empíricas a respeito de conceitos emergentes, tais como MIL - Media and Information Literacy (Literacias de Mídia e Informação), comportamento dos atores em rede, consumo e produção de conhecimento, novas formas de autoria e protagonismo na atual sociedade hiperconectada. Essas pesquisas visam a observar e a descrever as conexões que estruturam as tramas da rede e a analisar seus flexíveis eixos sociais, técnicos e sociotécnicos, privilegiando a utilização de métodos da etnografia virtual e da netnografia (KOZINETS, 2002).

O diálogo entre as atividades no âmbito da docência das disciplinas Recursos Informacionais I e II no curso de Graduação em Biblioteconomia e Documentação do Departamento de Informação e Cultura - CBD da ECA-USP e os estudos realizados pelo Nace Escola do Futuro USP levaram Passarelli a conceber e implantar um portal web para promover a construção do conhecimento discente em rede. O projeto de criar um ambiente virtual de aprendizagem e de prática contemplou uma proposta pedagógica que transpassa a ênfase na construção do conhecimento e o estímulo à autonomia. Como sinalizado em artigos sobre o Nexus (PASSARRELI, 2007, 2008, 2010), o portal ancora os conteúdos programáticos e estimula os alunos a construírem conhecimentos por meio da publicação de todas as atividades, individuais e coletivas, por eles realizadas.

A proposta pedagógica deste AVA - ambiente virtual de aprendizagem - agregou conceitos de ensino híbrido e de inteligência conectiva e inteligência distribuída, análises desenvolvidas por cognitivistas e cientistas da comunicação, como Gardner (1993), Hewitt e Scardamaglia (1996), e De Kerckhove (1997), entre outros. Também é possível identificar uma dinâmica de protagonismo dos alunos no AVA, o que se relaciona com as MIL - Literacias de Mídia e Informação. Segundo a Organização das Nações Unidas para a Educação, a Ciência e a Cultura (Unesco) ${ }^{1}$, as MIL constituem um dos requisitos mais importantes para fomentar o acesso igualitário ao conhecimento e à informação e para promover os meios e sistemas de comunicação mais livres e pluralistas. A Unesco reúne o campo da mídia e da informação sob o mesmo conjunto de competências necessárias (conhecimentos, habilidades e atitudes) para que se possa lidar com os meios de comunicação e outros provedores de informação (arquivos, museus, bibliotecas e internet). 
O debate sobre o tema tem ganhado uma agenda internacional desde maio de 2014, data em que ocorreu o $1^{\text {tt }}$ European Media and Information Literacy Forum $^{2}$ na sede da Unesco, em Paris. Organizada pela Comissão Europeia, pela Unesco e coorganizada pelo Projeto Emedus e o Gabinete de Comunicación y Educación da Universidade Aberta de Barcelona, a iniciativa reuniu profissionais de mídia e informação, especialistas, pesquisadores, representantes de governos e de indústrias, entre outros, para debater a importância de uma educação para as literacias de mídia e de políticas e iniciativas transnacionais sobre o tema. Passarelli participou do fórum como representante brasileira e pesquisadora da USP com trabalhos publicados sobre esse viés desde 2007. Na ocasião identificou que os pesquisadores presentes e as instituições organizadoras reconhecem que as MIL são essenciais para o desenvolvimento e a compreensão de questões relacionadas ao ensino e à aprendizagem, notadamente cada vez mais presentes on-line.

\section{Atributos do AVA Nexus - da Informação ao Conhecimento}

O reconhecimento da importância das plataformas digitais para a educação e o interesse em incorporar as TIC nos contextos de ensino-aprendizagem foram dois aspectos fundamentais para a idealização do AVA Nexus - da Informação ao Conhecimento. A versão embrionária do AVA foi concebida e inaugurada em 2000. No ano seguinte ocorreu sua implantação ${ }^{3}$, já ancorando os conteúdos de Recursos Informacionais I (disciplina obrigatória de dois créditos ministrada para alunos da Graduação em Biblioteconomia do quarto período) e Recursos Informacionais II (disciplina obrigatória de quatro créditos ministrada para alunos de Graduação em Biblioteconomia do quinto período). Naquele momento, o objetivo do uso de um ambiente virtual de aprendizagem na graduação foi incrementar a motivação do aluno e a interação aluno-aluno e aluno-professor, propiciando formas de interação que levariam à construção autônoma do conhecimento e do conceito de autoria na web.
Desde o princípio, o portal está ancorado em um servidor Linux do Nace Escola do Futuro USP. A interface utiliza linguagem de programação Java, aliada a um banco de dados relacional. As aulas presenciais ocorrem em sala no CBD equipada com cerca de vinte laptops conectados à rede wi-fi da USP. A navegação dos alunos no portal é intuitiva, uma vez que as seções foram organizadas para facilitar o acesso discente.

\section{Seções do AVA Nexus - da Informação ao Conhecimento}

Na seção Disciplinas, o aluno encontra informações sobre as disciplinas Recursos Informacionais I e II, o objetivo de cada uma delas, o cronograma das aulas e o respectivo conteúdo em formato de hipertexto com links para artigos e dados correlatos, bem como as atividades propostas e o local para essas atividades.

Em Pesquisa encontram-se informações relativas à produção do conhecimento organizadas em Metodologia, Comunicação, Bibliografia e Sites. Na subseção Metodologia há conceitos de metodologia do trabalho e questões como: o que é conhecimento, o que é pesquisa, como fazer um resumo, uma resenha, um esquema e um quadro sinótico. Além de um roteiro para elaborar um projeto de pesquisa científica. Em Comunicação, encontram-se as orientações voltadas para a redação do texto, no que se refere aos níveis de linguagem, unidade temática, parágrafo, processos argumentativos e coesão textual. Já em Bibliografia e Sites estão as indicações de referências bibliográficas e de sites que dão embasamento para os temas a serem tratados nas respectivas disciplinas.

A seção Inter-Ação é o espaço dedicado para ancorar a produção dos alunos, o que está diretamente associado ao tipo de aula previamente definido no cronograma de cada disciplina. As aulas externas dedicam-se à elaboração de resumos e resenhas de artigos científicos e/ou capítulos de livros a serem publicados como Atividade Individual. As Atividades Coletivas contemplam as postagens dos seminários temáticos desenvolvidos ao longo do semestre e do trabalho final da disciplina, que 


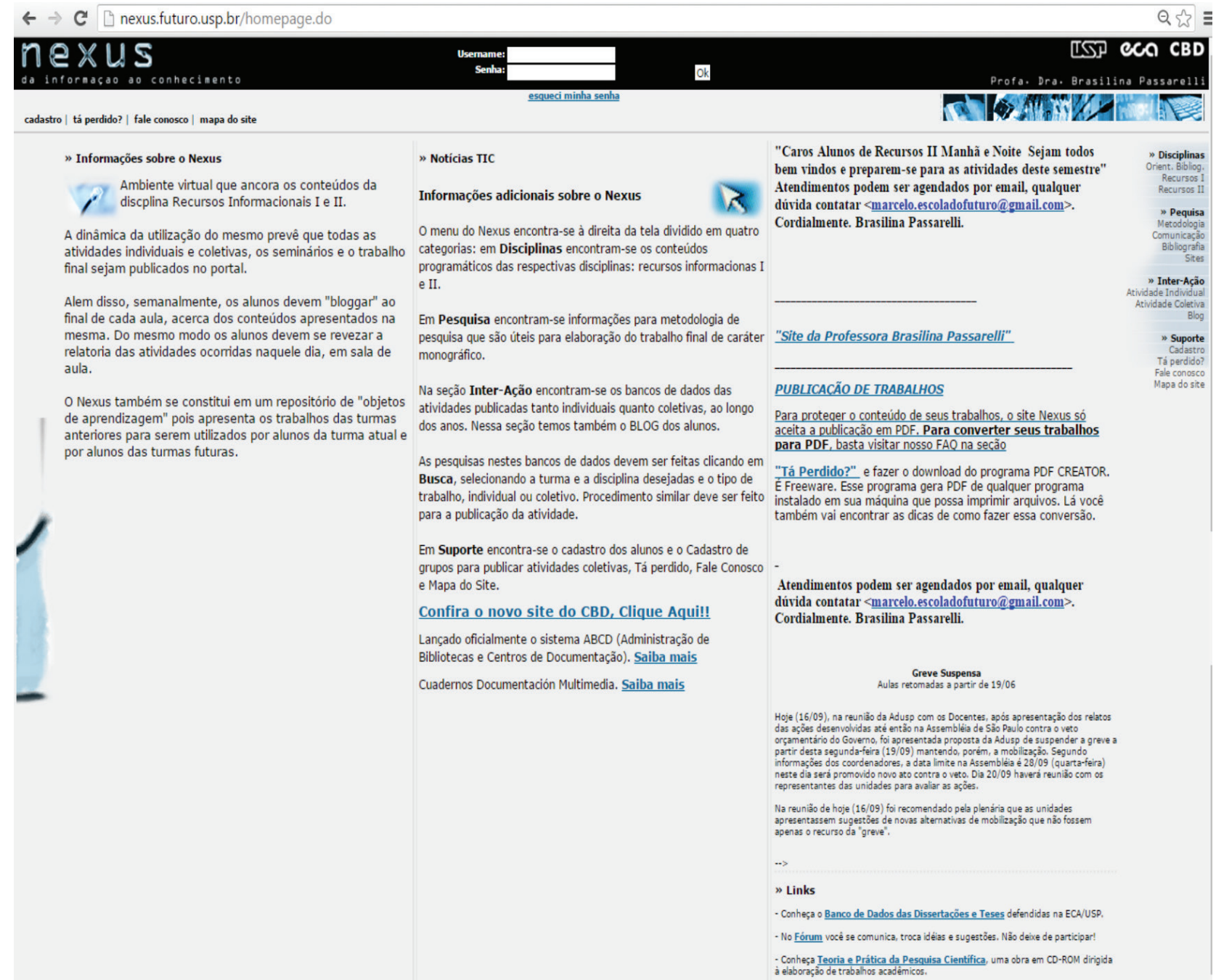

Figura 1 - Nexus - da Informação ao Conhecimento: página de entrada.

constitui um Manual de Obras de Referência, em qualquer área do conhecimento por eles eleita. Ambas as atividades estão disponíveis no AVA Nexus desde 2002. Em 2006 foi incorporada a publicação de Blogss nas disciplinas, permitindo que o aluno desenvolvesse uma produção mais autoral focada em temas que se relacionam com o conteúdo da aula e, do ponto de vista do formato, customizada como um documento multimídia. As três formas de produção, Atividades Individuais, Atividades Coletivas e Blogs, constituem subseções que representam a oportunidade de produção de conhecimento no AVA.

A seção Suporte oferece apoio às demais seções. Por exemplo, o aluno se cadastra para participar das atividades. Na subseção Tá Perdido? encontram-se informações que orientam a navegação, indicando seções e espaços correspondentes às ati- vidades do próprio portal. Uma equipe de suporte e/ou a professora podem ser contatadas pelo Fale Conosco. No Mapa do Site consta a arquitetura de informação do site com as seções e subseções aqui descritas, tudo acessível através de hiperlink para cada conteúdo correspondente.

\section{Principais Indicadores da Produção Discente no Nexus - da Informação ao Conhecimento}

A fim de compreender a dimensão da produção de conhecimento em rede pelos alunos das disciplinas Recursos Informacionais I e II, este texto contempla os resultados da primeira pesquisa de Marketing da Informação (PASSARELLI \& SILVEIRA, 2008), cujos dados se referem ao período de 2002 a 2007 (semestre com números totais não finalizados). Somou-se a esse montante um número estimado da produção de atividades individuais, 


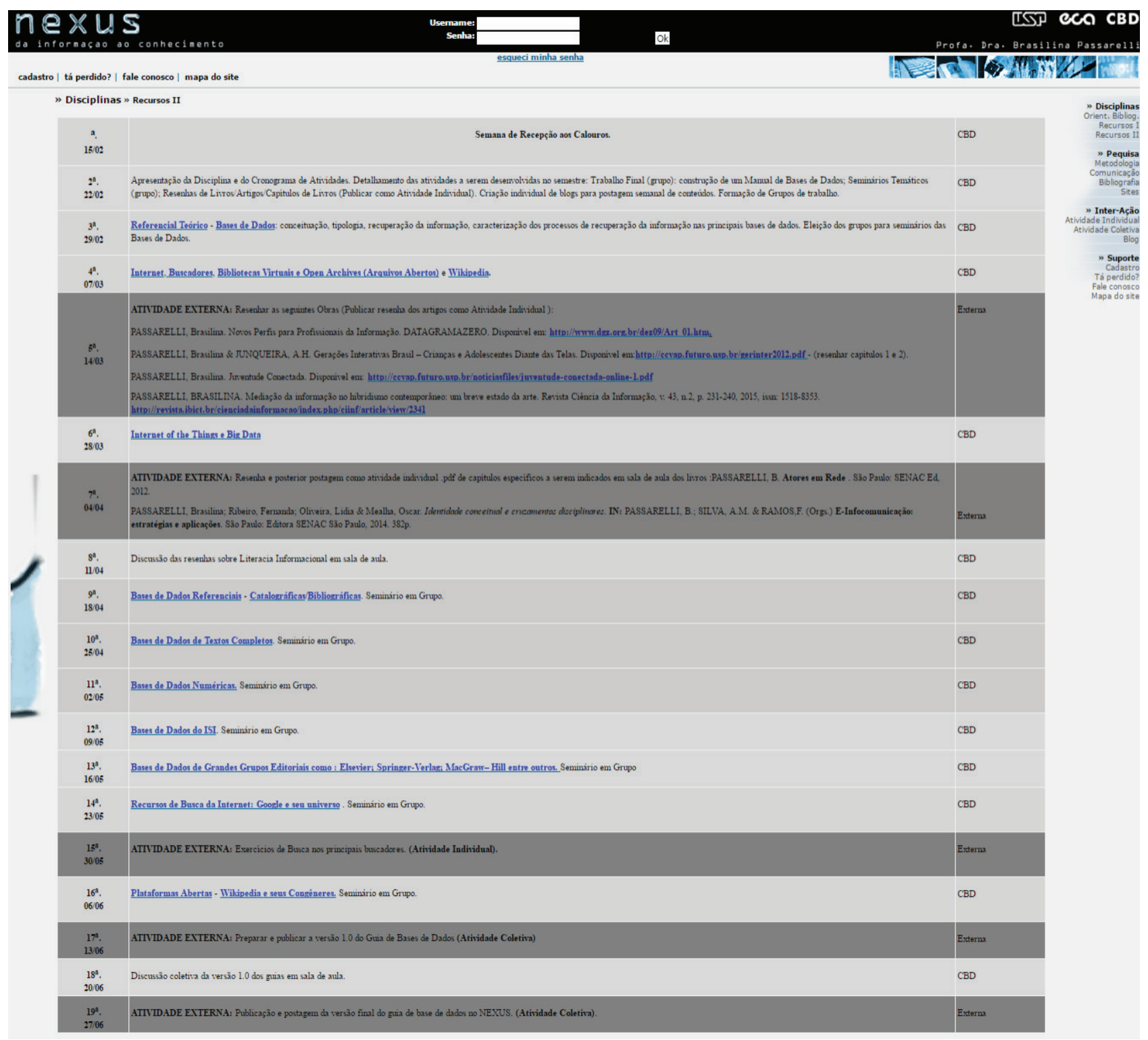

Figura 2 - Nexus: Cronograma da disciplina Recursos Informacionais II. Fonte: <http://nexus. futuro.usp.br/view.do?page $=21>$.

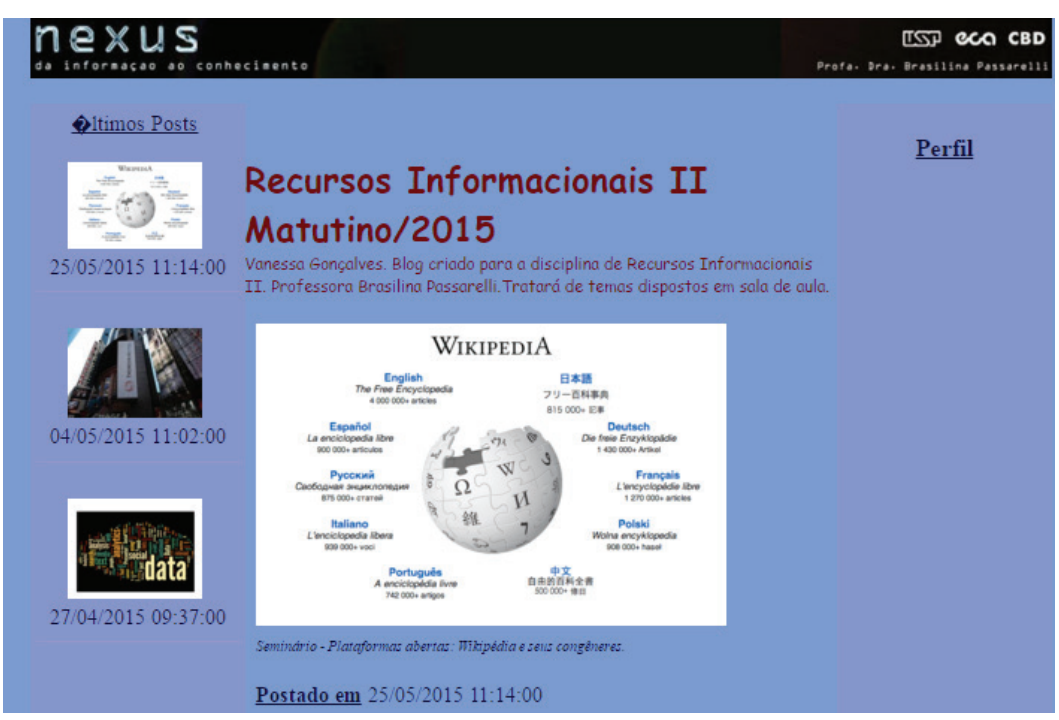

Figura 3 - Nexus: Blog de Aluno. Fonte: বhttp://nexus.futuro.usp.br/ blog/ vanessa $>$. 
atividades coletivas, blogs e posts de blogs de 2008 a 2015 .

Mostra-se importante considerar que o cálculo de atividades individuais e atividades coletivas se baseou na distribuição por semestre, com cerca de vinte alunos por turma (manhã e noite), sendo quarenta alunos por semestre (2002-2007), e com cerca de dez alunos por turma (manhã) e vinte alunos por turma (noite), totalizando trinta alunos por semestre (2008-2015). A proporção de alunos varia conforme a oferta: a disciplina Recursos Informacionais I é ministrada geralmente no segundo semestre, e a Recursos Informacionais II no primeiro semestre do ano seguinte. A quantidade de Blogs corresponde ao número exato ${ }^{3}$ de diários virtuais publicados na web. $\mathrm{O}$ número de postagens nos blogs é aproximado, resultante da multiplicação do número de blogs (por ano) por 7 , quantidade média de posts (por aluno). Exceção de postagem foram os anos de 2011 a 2013, quando a disciplina no curso noturno foi oferecida por um docente visitante e o Nexus não foi utilizado para a postagem das atividades dos alunos.

Além disso, vale salientar que o Nexus indica a capacidade de produção discente da turma no semestre vigente, bem como se constitui num repositório de objetos de aprendizagem, a exemplo da Rede Interativa Virtual de Educação (Rived) ${ }^{4}$, programa da Secretaria de Educação a Distância (Seed) do Ministério da Educação. Tais objetos digitais de aprendizagem, como textos, imagens, animações, vídeos, simulações, blogs e outros, podem ser utilizados em diferentes momentos do processo educacional e em variados ambientes de aprendizagem. Os gráficos de 1 a 5 condizem com as seguintes produções: Gráfico 1-Atividades Individuais Publicadas; Gráfico 2 - Atividades Coletivas Publicadas; Gráfico 3 - Blogs Publicados; Gráfico 4 - Posts Publicados nos Blogs; Gráfico 5 - Panorama da Produção Discente 2002-2015.

Como a versão alfa do Nexus, de 2001, não possuía módulo para atividades, a produção

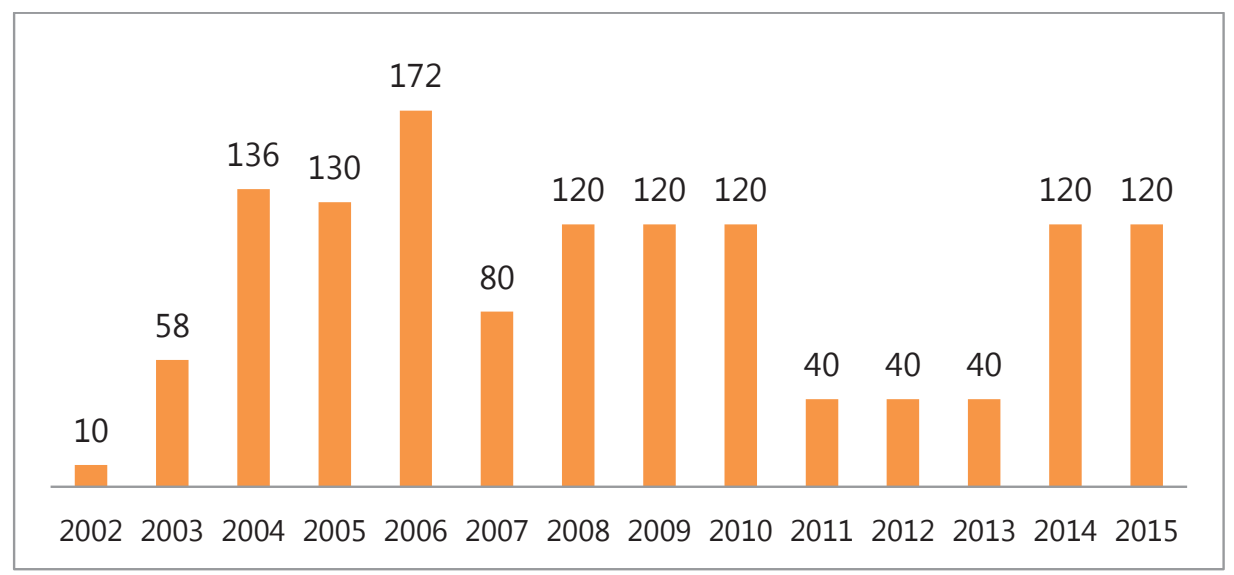

Gráfico 1 - Atividades Individuais Publicadas. Fonte: as autoras.

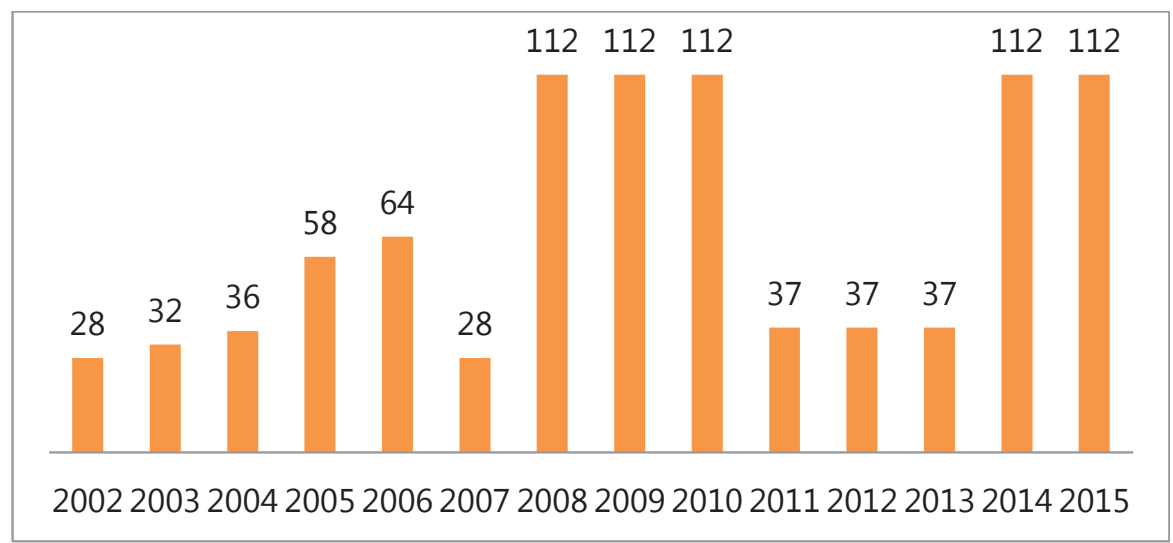

Gráfico 2 - Atividades Coletivas Publicadas. Fonte: as autoras. 
discente era publicada diretamente em um fórum. Essa ferramenta foi criada em $2002 \mathrm{e}$, daquele ano até 2005, observou-se um aumento crescente de publicações individuais. Conforme observado na primeira pesquisa de Marketing da Informação (PASSARELLI \& SILVEIRA, 2008), tal incremento levou à oferta de um blog individual para postagens mais amplas, com comentários sobre os seminários temáticos dos colegas e os seminários dos trabalhos finais.

As atividades coletivas contemplam seminários temáticos realizados em grupo e monografia temática em grupo, que constitui o trabalho final da disciplina. $\mathrm{O}$ aumento do número dessa produção

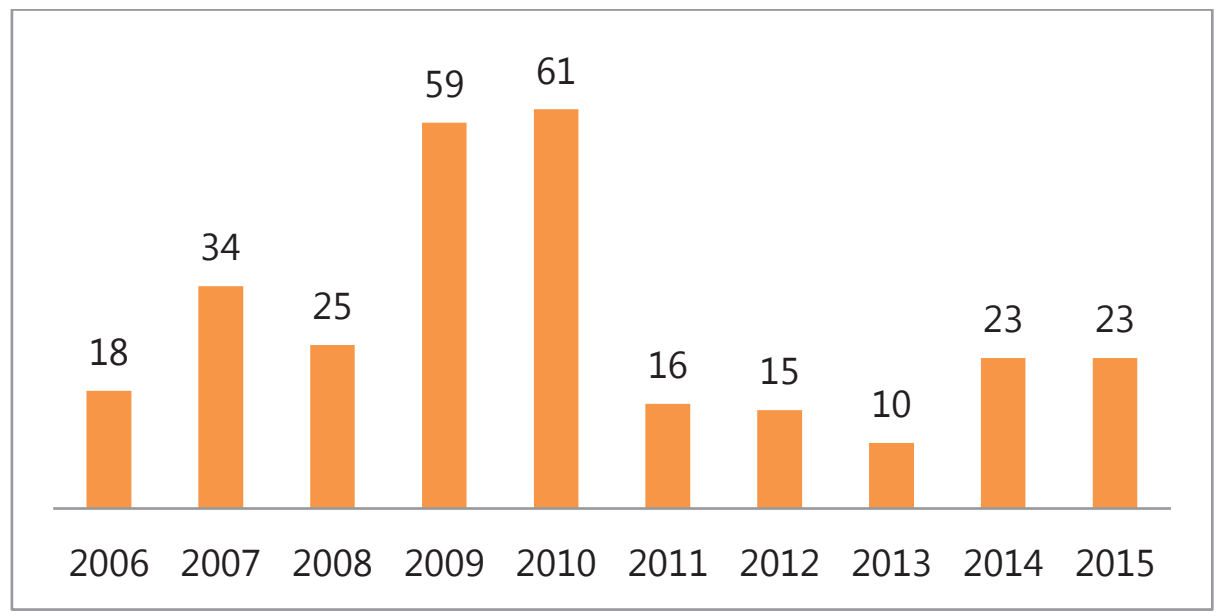

Gráfico 3 - Blogs Publicados. Fonte: as autoras.

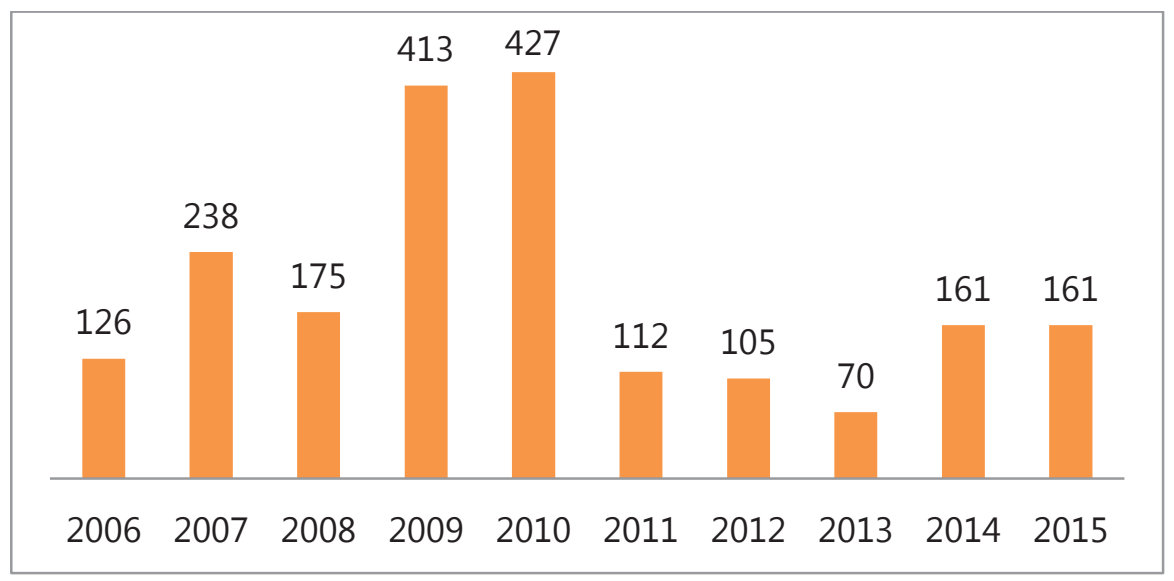

Gráfico 4 - Posts Publicados nos Blogs. Fonte: as autoras.

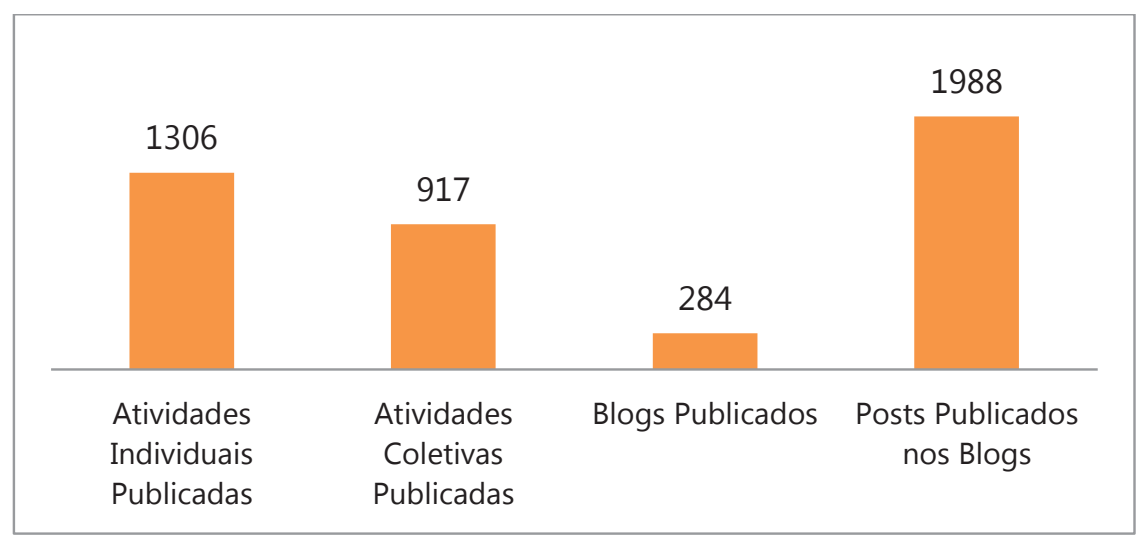

Gráfico 5 - Panorama da Produção Discente 2002-2015. Fonte: as autoras. 
revela o estabelecimento de uma nova relação com o saber, uma vez que se observam, sobretudo no início dos anos 2000, a velocidade de surgimento e renovação de saberes e uma amplificação, exteriorização e modificação de numerosas funções cognitivas humanas, tais como memória, imaginação, percepção e raciocínios (LÉVY, 1999). A proposição de mais produções coletivas acompanha a importância de se ter uma política de mídia capaz de habilitar as crianças e os jovens a exercitarem suas novas competências adquiridas. Para tanto, Passarelli (2014) sinaliza a necessidade de inserção das disciplinas sobre as MIL na grade curricular e o convencimento do governo acerca do papel vital de tal disciplina para a formação do cidadão contemporâneo.

Como indicado anteriormente, o espaço para os blogs foi implantado em 2006 por causa de uma demanda de publicação de atividades individuais. Cumpre ressaltar que até 2010 a carga horária de ambas as disciplinas ofertadas era de quatro créditos. A partir de 2011, devido a uma reforma curricular, Recursos Informacionais I passou a contar com dois créditos. Portanto, o blog passou a ser realizado somente em Recursos Informacionais II. Isso explica a diminuição acentuada do número de blogs publicados a partir de 2011. Entretanto, esses não são os únicos fatores responsáveis pelos números aqui apresentados. Não é difícil observar que os avanços das TIC, principalmente no que se refere à multiplicidade das redes sociais, em geral, reverberaram nas práticas dos alunos em rede.

A quantidade de posts nos blogs segue a mesma proporção do Gráfico 3, uma vez que o número de posts é fruto de uma multiplicação da quantidade de blogs por sete posts por aluno.

O panorama das publicações discentes (20022015) revela uma mudança importante em termos de produção de conhecimento individual e coletivo. O Nexus configurou-se como uma proposta pioneira de interação aluno-aluno e professor-aluno. Essa afirmação baseia-se na crescente participação discente representada pela quantidade de trabalhos postados: mais de 1300 atividades individuais e novecentas atividades coletivas, e quase trezentos blogs e 2 mil posts publicados nos blogs - ao longo de treze anos.

\section{Considerações Finais}

A concepção e a implantação do Nexus - da Informação ao Conhecimento em 2000, no âmbito das disciplinas Recursos Informacionais I e II, para os alunos de quarto e quinto período do curso de Graduação em Biblioteconomia e Documentação da Escola de Comunicações e Artes da Universidade de São Paulo (ECA-USP), constituíram um projeto de vanguarda, estimulando o hibridismo de curso presencial ancorado num AVA - Ambiente Virtual de Aprendizagem e funcionando como plataforma de publicação de atividades individuais e coletivas dos alunos e também como LOR (learning objects repository), repositório de objetos de aprendizagem dos mesmos. Sua construção como repositório de objetos de aprendizagem possibilitou o uso de materiais digitais multimídia produzidos pelos discentes, permitindo que eles se expressassem através de diferentes linguagens e literacias de mídia e informação, dando vazão ao conceito emergente de MIL - Literacias de Mídia e Informação, anteriormente apresentado. O Nexus também fomenta o protagonismo dos alunos como atores em rede nas postagens de blogs pessoais temáticos. A atuação dos discentes aproxima-se de um ideal de agente transformador, segundo o qual todos podem contribuir para a produção de conhecimento e, assim, acabam por reconfigurar o ambiente da sala de aula e os papéis de professor e aluno. Por fim, vale considerar que este artigo empenha-se em apresentar alguns resultados significativos para os campos que possuem imbricamento com áreas como ciência da informação, comunicação e educação. Certamente, serão possíveis novas abordagens e contribuições para delinear os contornos dos ambientes educacionais do futuro.

\section{Notas}

1 Unesco. Disponível em: \http://www.unesco.org/new/ en/communication-and-information/media-development/media-literacy/mil-as-composite-concept $>$. 
2 Unesco. Disponível em: <http:/www.unesco.org/ new/en/communication-and-information/resources/ news-and-in-focus-articles/all-news/news/unesco partners_with_european_commission_to_launch_ european_media_and_information_literacy_forum/\#.VwEhcPkrLIU>.

3 Ver: <http://nexus.futuro.usp.br/homepage.do;jsessionid=262BCA00622DB384DD0D596FD638D73C>.

4 Conforme a relação de Blogs publicados. Disponível em: $\langle$ http://nexus.futuro.usp.br/blog/>.

5 Rived. Disponível em: <http://rived.mec.gov.br/site_ objeto_lis.php>.

\section{Referências Bibliográficas}

DE KERCKHOVE, D. A Pele da Cultura: uma Investigação sobre a Nova Realidade Eletrônica. Lisboa: Relógio D'Água, 1997.

FLORIDI, L. The Onlife Manifesto: Being Human in a Hyperconnected Era. London: Springer, 2013.

GARDNER, H. Multiple Intelligences: the Theory in Practice. New York: Basic Books, 1993.

HEWITT, J. \& SCARDAMAGLIA, M. "Design Principles for the Support of Distributed Processes". Symposium on Distributed Cognition: Theoretical and Practical Contributions. New York: Annual Meeting of the American Educational Research Association, 1996.

KOZINETS, R. V. "The Field Behind the Screen: Using Netnography for Marketing Research in Online Communities". Fournal of Marketing Research, vol. 39, pp. 6172, Feb. 2002. Disponível em: http://www.nyu.edu/classes/ bkg/methods/netnography.pdf. Acessado em $1^{\circ}$ fev. 2016.

LATOUR, B. Reassembling the Social: an Introduction to Actor- Network-Theory. New York: Oxford University Press, 2005.

LÉVY, P. Cibercultura. São Paulo: Editora 34, 1999.
PASSARELLI, B. "Mediação da Informação no Hibridismo Contemporâneo: um Breve Estado da Arte". Ciência da Informação. Brasília, DF, vol. 43, n. 2, pp. 231-240, maio/ago. 2014. Disponível em: http:// revista.ibict.br/ciinf/article/view/1406. Acessado em 26 mar. 2016.

"Virtual Learning Environments Incorporated into In-Person Learning in the Graduation Programs of Library Science and Documentation at ECA/ USP: the Experience of Nexus Portal: from Information to Knowledge". In: LARA, Marilda Lopes Ginez de; FUJINO, Asa \& NORONHA, Daisy Pires. (orgs.). Information and Contemporaneity: Perspectives. Recife: Néctar, 2010, vol. 1, pp. 281-294.

"Web Knowledge Production and Publication in Information Science Teaching: a Case Study on Portal Nexus - from Information to Knowledge". Second International Symposium on Knowledge Communication and Peer Reviewing: KCPR 2007, 2007, Orlando, Florida. Proceedings - The Second International Symposium on Knowledge Communication and Peer Reviewing: KCPR 2007. Orlando, FL.: International Institute of Informatics and Systemics - IIIS, 2007, vol. 3, pp. 225-229.

\& SILVEIRA, A. "O Portal Nexus - da Informação ao Conhecimento e o Marketing da Informação na Comunidade de Alunos da Graduação no CBD/ ECA/USP". Prisma.com, vol. 7, n. 13, pp. 44-59, 2008.

UNESCO. Media and Information Literacy. Disponível em: <http://www.unesco.org/new/en/communication-and-information/media-development/media-literacy/ mil-as-composite-concept/>. Acessado em $1^{\circ}$ fev. 2016.

News and In Focus Articles. Disponível em: $<\mathrm{http}: / /$ www.unesco.org/new/en/communication-and-information/resources/news-and-in-focus-articles/all-news/ news/unesco_partners_with_european_commission_to_ launch_european_media_and_information_literacy_forum/\#.VwEhcPkrLIU>. Acessado em 28 jan. 2016. 